\title{
Online mathematics teaching and learning during the COVID- 19 pandemic: The perspective of lecturers and students
}

\author{
F. Radmehr ${ }^{1,2}$, and S. Goodchild ${ }^{1}$ \\ ${ }^{1}$ University of Agder, ${ }^{2}$ Western Norway University of Applied Sciences
}

\begin{abstract}
The global spread of the novel coronavirus, Covid-19, reached Norway at the end of February 2020. MatRIC, Centre for Research, Innovation and Coordination of Mathematics Teaching conducted a national survey in Norwegian higher education institutions (HEIs) during June-July 2020 to explore lecturers' and students' experiences of online mathematics teaching and learning and to enable sharing of solutions to the challenges encountered. One hundred and twenty-seven students and eighteen lecturers participated in this survey. In this presentation, we will share some of the findings of the survey in relation to the following two themes: challenges of learning and teaching mathematics online, and the psychological impact of lockdown on student learning and lecturer teaching. The study findings show that many students missed the social contact, being physically present at the university, and face to face interaction with their lecturers. Additionally, several students experienced a degree of anxiety through the lockdown period to the extent that they perceived their learning was negatively affected. Lecturers took a number of steps to ensure lines of communication remained open. Our findings show that simple actions by the lecturer to open channels of communication can be very effective.
\end{abstract}

\section{INTRODUCTION}

The global spread of the novel coronavirus, Covid-19, reached Norway at the end of February 2020. As soon as the beginning of the second week in March 2020, it had become clear that the virus was spreading rapidly within the Norwegian population. On March 12, the Norwegian Government took emergency action and locked down the community restricting all non-essential activity with immediate effect. Universities were closed; lecturers and students were required to move to online teaching and learning from the following March 16. Some mathematics lecturers in Norway had been experimenting with digital tools for teaching and learning mathematics for some time before the lockdown. However, for many, the requirement to suddenly move to online teaching was an unwelcome shock for which they were not well prepared. MatRIC, Centre for Research, Innovation and Coordination of Mathematics Teaching is a Norwegian Centre for Excellence in Education. MatRIC aims to support mathematics lecturers and students in Norway by facilitating the exchange of ideas for good practices in all areas of mathematics teaching and learning. MatRIC conducted a national survey of online mathematics teaching and learning in Norwegian higher education institutions (HEIs) to explore lecturers' and students' experiences and enable the sharing of solutions to the challenges encountered. In this presentation, we will share some of the findings of this survey.

\section{ONLINE TEACHING AND LEARNING OF MATHEMATICS}

Online teaching, both synchronous and asynchronous, is not new, and there already exists a growing body of literature on this issue (e.g., Engelbrecht, \& Harding, 2005; Hollebrands, \& Lee, 2020; Joubert, 2013; Juan, Steegmann, Huertas, Jesus Martinez, \& Simosa, 2011). Despite several differences between face to face and online education, previous studies (e.g., Engelbrecht \& Harding, 2005; Joubert, 2013) highlighted that the basic principles of teaching and learning of mathematics should follow in an online environment; such as having a sound balance between teacher and learner-centred activities and creating opportunities for students to develop a relational understanding of mathematics, or from the commognitive perspective, making their transition from ritualised to explorative discourse. Previous studies (e.g., Engelbrecht \& Harding, 2005; Juan et al., 2011) also shed light on some of the benefits (e.g., independent learning; convenience, flexibility, and accessibility of learning) and challenges (e.g., lack of face-to-face contact) of online education, and we anticipate some of these themes also reported from our survey. 
Technological pedagogical content knowledge (TPACK) (Koehler \& Mishra, 2009; Mishra \& Koehler, 2006) is a framework that highlights the importance of technology in teacher knowledge while acknowledging the complexity of teacher knowledge. This framework claims that at the centre of effective teaching with technology are three core knowledge types: content, pedagogy, and technology (Mishra \& Koehler, 2008). The TPACK approach to making sense of teaching with technology does not perceive these three knowledge types in isolation, the relationships between them are equally important (Mishra \& Koehler, 2008). Furthermore, these types of knowledge interact differently across different contexts, and consequently, various approaches to the integration of technology in practice can be seen in different settings (Mishra \& Koehler, 2008). The TPACK framework acknowledges the importance of social and contextual factors teachers take into account when deciding how to integrate technology in their teaching (Mishra \& Koehler, 2009). There is considerable variation between social and contextual institutions. The extent to which the context encourages or restricts the integration of technology in teaching inevitably impacts on how teachers adapt their practice with the incorporation of technology.

\section{METHODOLOGY}

The creation of an instrument to explore experiences of a novel phenomenon such as the sudden and unexpected imposition of online teaching that occurred due to the Covid-19 crisis is particularly challenging. The danger is that the instrument reflects the restricted experiences of the researchers and does not explore sufficiently all the experiences of those who made the transition to online teaching and learning. To meet the challenge, we first interviewed a sample of 10 mathematics teachers and six students. We structured the interviews around several open questions that provided the respondents with the opportunity to describe their experiences. The questions were distributed to respondents in advance so they would have the opportunity to reflect on their experiences and consider how they would respond. Interviews were conducted online (using Zoom) and recorded. We based the next stage of developing the instrument on our analysis of responses from the interviews. The first draft of the instrument was produced in English and sent to several international experts in higher education mathematics teaching, learning support and university mathematics education research. Their reflections led us to make mainly structural modifications to the instrument rather than changes in the content or intent of items in the instrument. A second draft was produced in English and translated into Norwegian. An experienced mathematics lecturer checked the Norwegian translation. Following minor modifications to language, we distributed the instrument (Norwegian and English versions) using an online survey tool (SurveyXact) to mathematics lecturers in Norwegian HEIs through the MatRIC Contact Group. The survey conducted at the close of the Spring semester 2020. One hundred and twenty-seven students and 18 lecturers completed the survey.

\section{RESULTS}

This section describes the survey findings regarding two (out of five) of the main themes identified from data analysis.

\subsection{Challenges of learning and teaching mathematics online}

In the questionnaire, several items were associated with exploring the challenges of learning and teaching mathematics online. For each item, the participants could choose between six statements. The statements were different for lecturers and students. Students were asked which statement best fitted their experience: Did not experience at all, I experienced some challenge but I took effective action and did not suffer, I experienced some challenge and took some action to get help, but the challenge remained, experienced this moderately, experienced very much, and not applicable. Lecturers' choices were: Did not consider this as important or relevant, considered and felt it was students' responsibility to take action, considered and took some action, considered deeply and took moderate action, considered deeply and took strong action, and not applicable. Figures 1 to 3, show percentages of students that chose Experienced this moderately or Experienced very much, and what percentage of lecturers considered those challenges and took some, moderate or strong action toward it (numerical values of $\%$ are printed within the bars). 
The responses indicate that for ten out of the twelve items that were identified from the interviews, one in every three students experienced that item moderately or very much during the lockdown. Additionally, for four of these items, the percentages were above $50 \%$ (i.e., social isolation and missing friends and colleagues to work with; missing the routine and structure of coming to university and following the daily schedule; missing the availability or physical presence of the lecturer or student learning assistants to ask questions; and missing the live presentation of mathematics by a physically present lecturer).

Another observation form these responses is that for items that a high proportion of students experienced moderate or very much challenge during the lockdown, a fair percentage of lecturers perceived that they took some, moderate or strong action toward meeting that challenge. However, a closer look at the first two choices given to the lectures for these challenges (i.e., did not consider this as important or relevant, considered and felt it was students' responsibility to take action), indicate that many of the challenges were not anticipated or considered by the lecturers to be part of their responsibility. For instance, regarding students would experience increased anxiety because they have no other students to help them pace themselves or measure their own progress against, $72.2 \%$ selected the first two choices. Looking across the twelve challenges listed in the lecturer questionnaire, more than half of the lecturers selected the first two choices for seven of these challenges. It seems that the lecturers did not, did not want to, or were not able to imagine themselves into the experience of individual students and consider what they might do to support the students. This is most likely due to the novelty of the situation, and the fact that lecturers were most likely anxious about their own teaching practice.

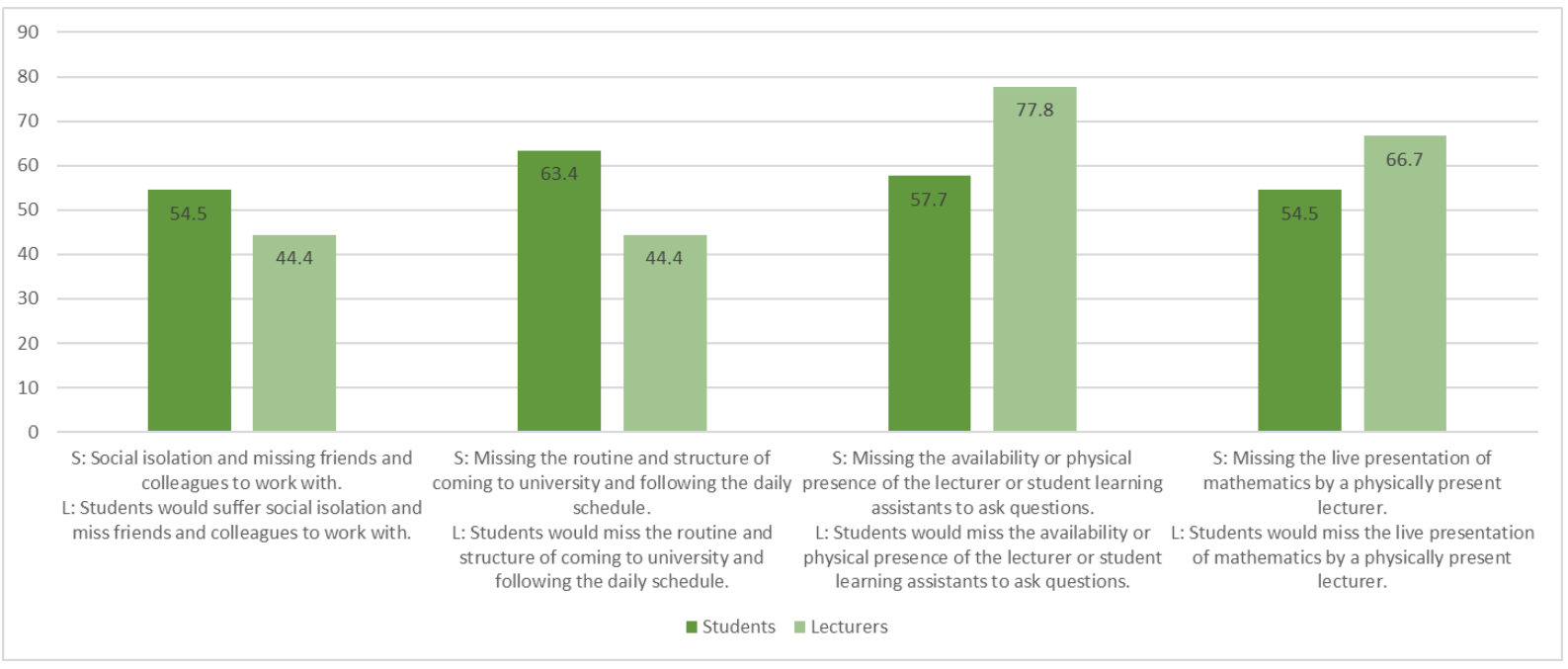

Fig. 1. The participants' perspectives on challenges students experienced during the lockdown (part 1)

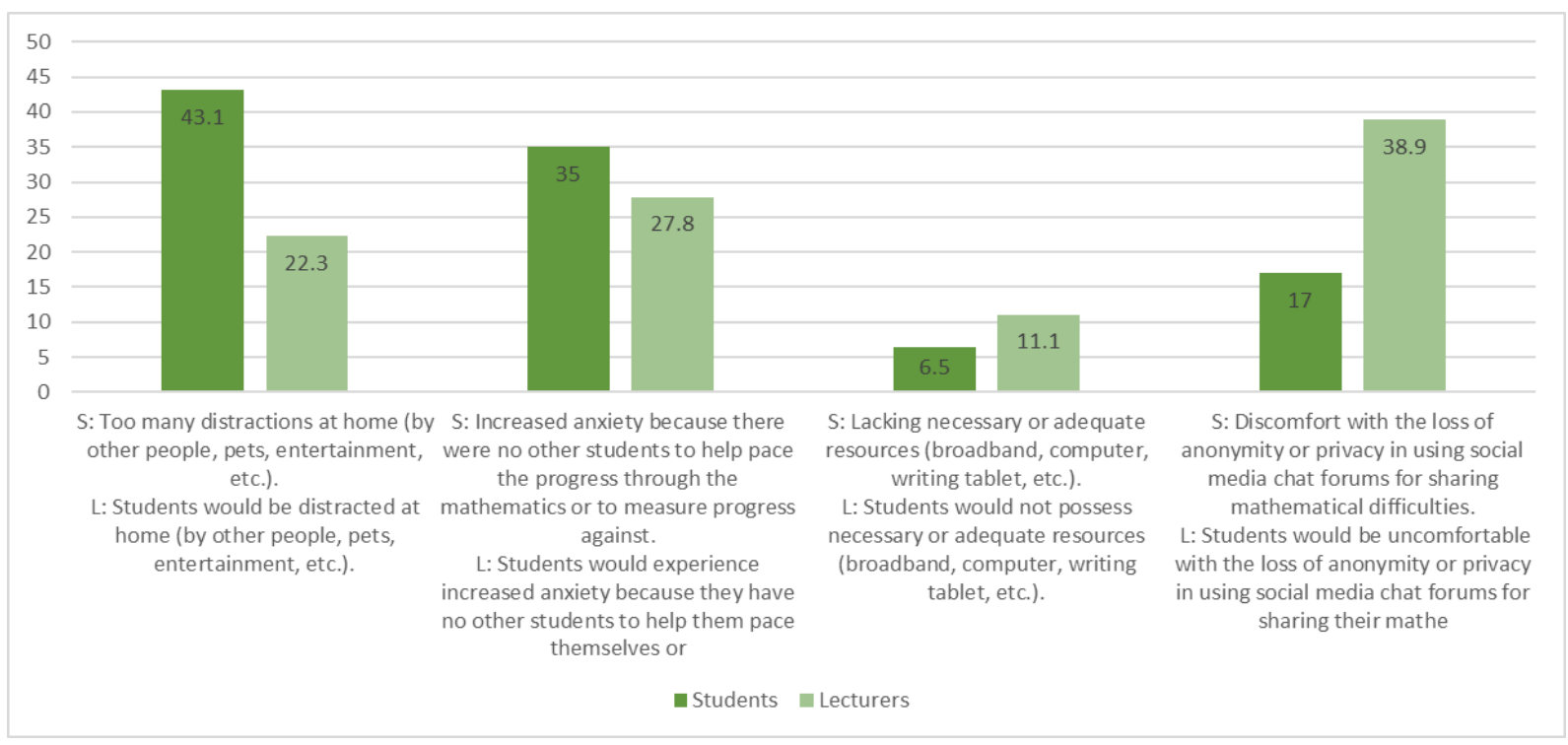

Fig. 2. The participants' perspectives on challenges students experienced during the lockdown (part 2) 


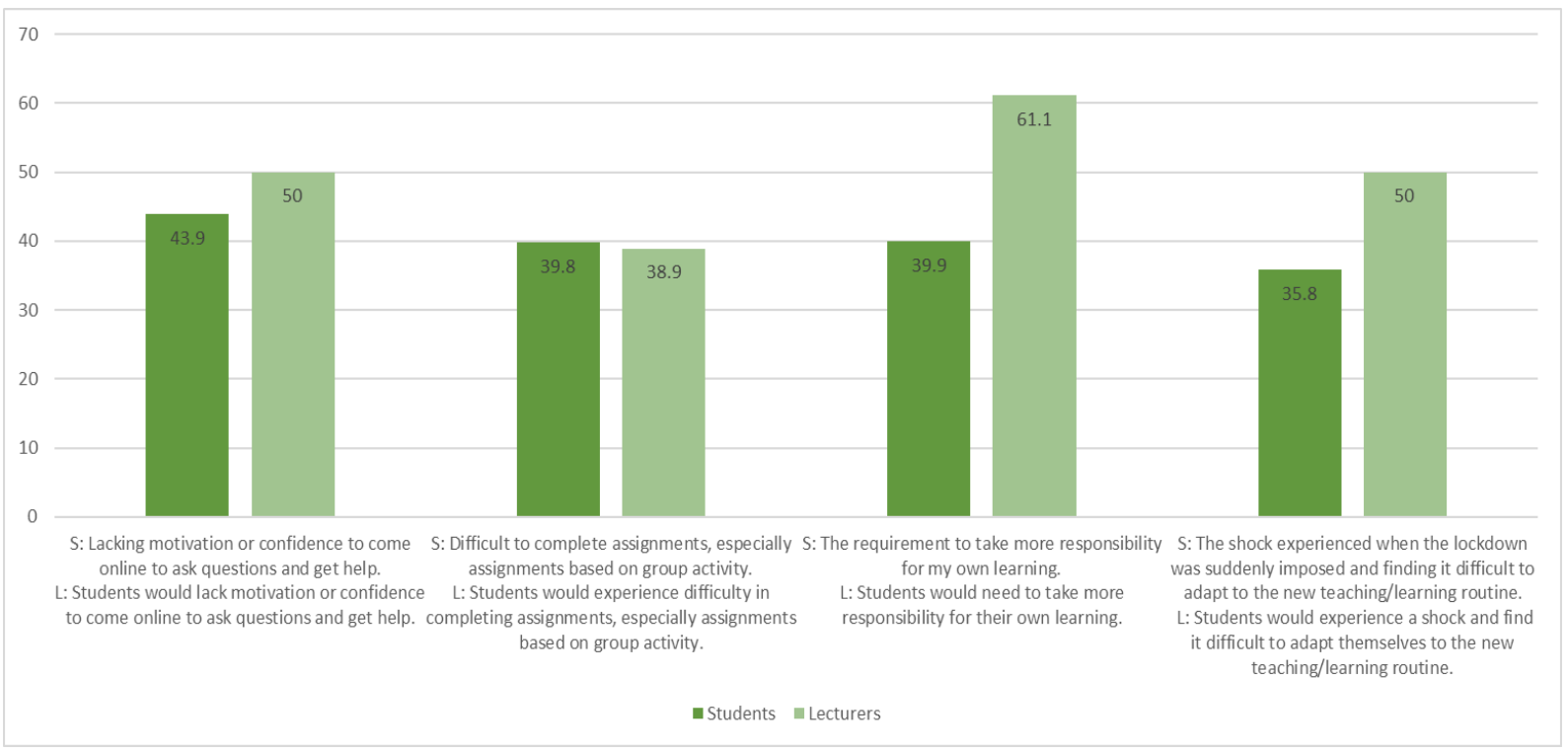

Fig. 3. The participants' perspectives on challenges students experienced during the lockdown (part 3)

\subsection{The psychological impact of lockdown on student learning and lecturer teaching}

Students and lecturers were invited to indicate to what extent they experienced the following issues affected their teaching/learning during the lockdown: 1. Fear for myself and/or my family of being infected by the virus; 2. Losing physical contact with family and friends; 3. Distractions of family and working at home; 4. Absence from workplace and colleagues; 5. Uncertainty about the future for myself and/or my family; 6. Depression; and 7. Financial issues for myself and/or my family. For each item, the participants could choose between five statements (i.e., not at all, a little, some, very much, I prefer not to comment). Figure 4 shows the percentage of participants that chose some or very much. Considering the Norwegian context, lecturers were not given item 7. Around $20 \%$ to $40 \%$ of students responded that these items affected their learning some or very much. Additionally, at least one in every three students perceived that absence from workplace and colleagues, losing physical contact with family and friends, and distraction of family and working at home affected their learning some or very much during the lockdown.

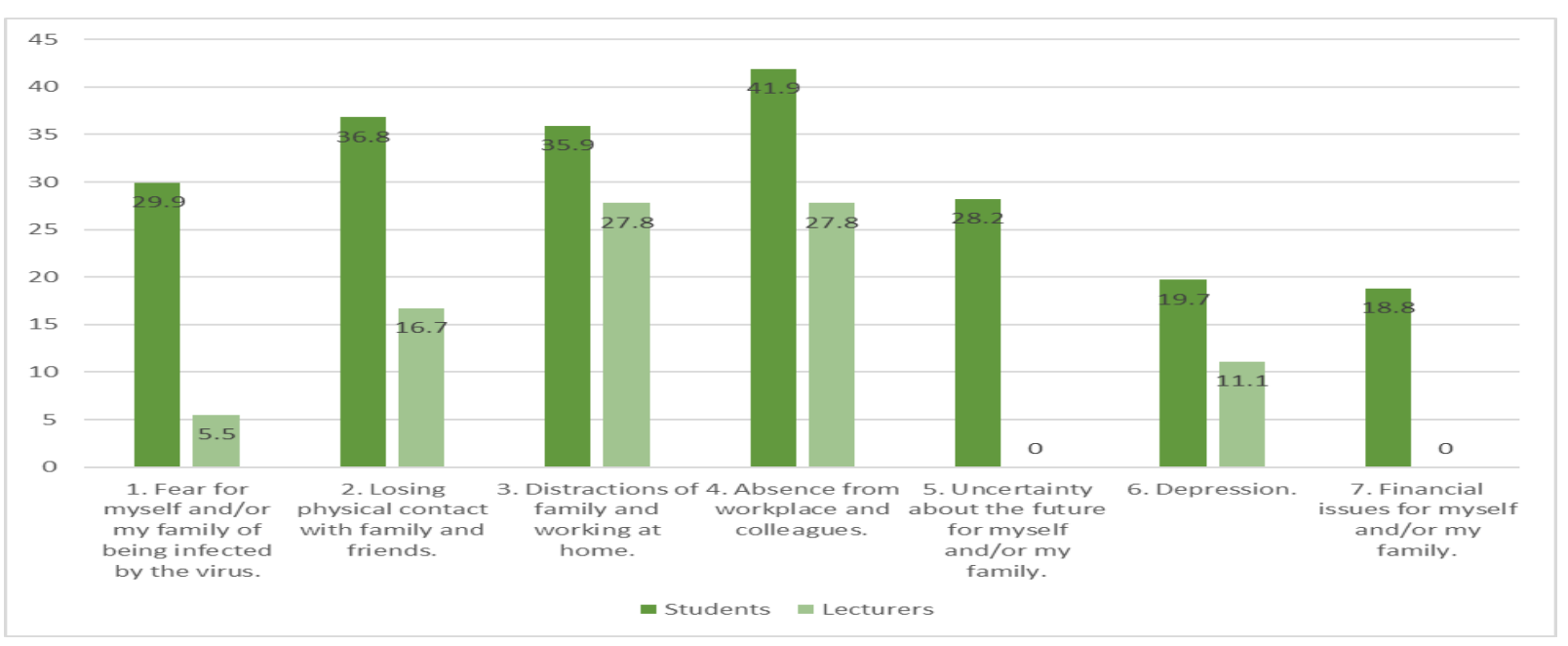

Fig. 4. The psychological impact of lockdown on student learning and lecturer teaching

\section{DISCUSSION AND CONCLUSIONS}

Lecturers' Technological Knowledge (TK), for many, has expanded during the lockdown. Many more are familiar with online video lectures (synchronous) or recording lectures for asynchronous viewing. For some, it has been a steep learning curve, for others a natural development. As one lecturer 
highlighted in the interviews, the mathematics does not change; it is only a matter of thinking how to present the mathematics using the new medium.

Some experienced lecturers mentioned in the interviews that their use of technology in teaching was limited before the corona situation. They further elaborated that it takes time for them to learn how to work with online platforms for teaching, such as using breakout rooms in Zoom (i.e., lack of Technological Pedagogical Knowledge (TPK)). Additionally, some lecturers were not familiar with online platforms that can be used for communications between students, lecturers, and SLAs (e.g., Piazza), another indication of lack of TPK.

The descriptive statistics shared here suggest that universities and lecturers need to be mindful of the wellbeing of their students and how that impacts their learning, related to lecturers' TPK. Around 40\% of students experienced a degree of anxiety through the lockdown period to the extent that they believe their learning was negatively affected. Live interaction between lecturers and students clearly suffered during the lockdown. Lecturers took a number of steps to ensure lines of communication remained open, primarily through learning management software (e.g., Canvas), email, and Zoom. The lack of being physically present at the university and missing social contact were high among the negative consequences experienced by students. Also, the requirement that students take more responsibility for their work was keenly felt by many. Students want communication that is: live, anonymous, timely, functional and announced in advance. Simple actions by the lecturer to open channels of communication can be very effective.

Lecturers with high TPK who are sensitive to the impact on students learning and emotional welfare, and who are aware of how the impact can be reduced, can make a positive difference. Whether prompted by the lockdown, or for other reasons, there are many digital "solutions" to meet the challenges of teaching and learning mathematics online. It could be a valuable exercise to establish a form of "information exchange" in which challenges and solutions are shared. This is something that MatRIC might try to set up and coordinate, but it will only be effective as it used by the mathematics teaching and learning community. If online teaching and learning were to become a significant part of higher mathematics education, it would be necessary to work out responsibilities, structures, and strategies to address the challenges students experience.

\section{REFERENCES}

Engelbrecht, J., \& Harding, A. (2005). Teaching undergraduate mathematics on the internet. Part 2: Attributes and possibilities. Educational Studies in Mathematics, 58(2), 253-276.

Hollebrands, K.F., Lee, H.S. Effective design of massive open online courses for mathematics teachers to support their professional learning. ZDM, 52, 859-875 (2020). https://doi.org/10.1007/s11858-020-01142-0

Joubert, M. (2013). Using digital technologies in mathematics teaching: developing an understanding of the landscape using three "grand challenge" themes. Educational studies in mathematics, 82(3), 341-359.

Juan, A. A., Steegmann, C., Huertas, A., Jesus Martinez, M., \& Simosa, J. (2011). Teaching mathematics online in the European Area of Higher Education: an instructor's point of view. International Journal of Mathematical Education in Science and Technology, 42(2), 141-153.

Koehler, M. J., \& Mishra, P. (2009). What is technological pedagogical content knowledge (TPACK)? Contemporary Issues in Technology and Teacher Education, 9(1), 60-70.

Mishra, P., \& Koehler, M. J. (2006). Technological pedagogical content knowledge: A framework for teacher knowledge. Teachers College Record, 108(6), 1017-1054. 